\title{
Desafios e possibilidades do ensino remoto no contexto universitário durante a pandemia da COVID-19
}

Challenges and possibilities of remote teaching in the university context during the COVID-19 pandemic

Retos y posibilidades de la enseñanza a distancia en el contexto universitario durante la pandemia del COVID-19

Natália Kecia Barbosa de Lima

ORCID: https://orcid.org/0000-0002-6066-9393

Centro Universitário Vale do Salgado, Brasil

E-mail: enfnataliakecia@gmail.com

Francisco Matheus Bezerra Silva

ORCID: https://orcid.org/0000-0002-9069-7782

Universidade Federal de Campina Grande, Brasil

E-mail: matbezerra01@gmail.com

Ana Vilhena Araujo dos Santos

ORCID: https://orcid.org/0000-0002-1518-8339

Centro Universitário Doutor Leão Sampaio, Brasil

E-mail: ana_vilhenaaraujo@ hotmail.com

Igor Pereira de Oliveira

ORCID: https://orcid.org/0000-0002-5793-2752

Centro Universitário Vale do Salgado, Brasil

E-mail: igor.psi2018@gmail.com

Lauradella Geraldinne Sousa Nóbrega

ORCID: https://orcid.org/0000-0001-9282-5883

Universidade Federal de Campina Grande, Brasil

E-mail: laura.della@hotmail.com

Cícero Gonçalves Pereira

ORCID: https://orcid.org/0000-0002-0328-0285

Centro Universitário Doutor Leão Sampaio, Brasil

E-mail: cicinhopereira88@gmail.com

Jéssica Silva Félix dos Santos

ORCID: https://orcid.org/0000-0002-9006-7350

Centro Universitário Vale do Salgado, Brasil

E-mail: Wilmerson_ico@hotmail.com

Maiara Gadelha de Sousa

ORCID: https://orcid.org/0000-0002-6245-8012

Centro Universitário Vale do Salgado, Brasil

E-mail: Gadelha193@gmail.com

\section{Resumo}

O ensino remoto foi implementado de forma emergencial como uma alternativa para o ensino acadêmico. O estudo objetivou identificar, por meio da literatura, os desafios e possibilidades do ensino remoto no contexto universitário 
durante a pandemia da COVID-19. O estudo foi desenvolvido através de uma revisão integrativa da literatura, por meio da síntese de estudos voltados à temática referente aos desafios e possibilidades do ensino remoto no contexto universitário durante a pandemia da COVID-19. Foram utilizados 07 artigos para o estudo. Desta forma, foram estabelecidas duas categorias temáticas, sendo elas: (I) Desafios do ensino remoto no contexto universitário durante a pandemia da COVID-19 e (II) Possibilidades do ensino remoto no contexto universitário durante a pandemia da COVID-19. A primeira categoria enfatiza as principais dificuldades presentes na literatura referente aos desafios do ensino remoto durante a pandemia, que foram destacadas da seguinte forma: mudanças repentinas para o manuseio das tecnologias e plataformas educacionais para o ensino virtual. Já a segunda categoria destacou a articulação do processo de ensino e aprendizagem para a aplicabilidade da forma remota, uma vez que os impactos negativos para o ensino em tempos de pandemia foram superados com o avanço das tecnologias para a mediação das aulas realizadas em ambientes virtuais de aprendizagem. Desta forma, o ensino remoto trouxe possibilidades para o processo de ensino e aprendizagem no contexto universitário em tempos de pandemia da COVID-19, onde mostrou diferentes adaptações para o processo pedagógico e rotina acadêmica.

Palavras-chave: Aprendizagem; Ensino; Inovação.

\begin{abstract}
Remote teaching was implemented as an emergency alternative to academic teaching. The study aimed to identify, through the literature, the challenges and possibilities of remote teaching in the university context during the COVID19 pandemic. The study was developed through an integrative literature review, through the synthesis of studies focused on the theme regarding the challenges and possibilities of remote teaching in the university context during the COVID-19 pandemic. 07 articles were used for the study. In this way, two thematic categories were established, namely: (I) Challenges of remote teaching in the university context during the COVID-19 pandemic and (II) Possibilities of remote teaching in the university context during the COVID-19 pandemic. The first category emphasizes the main difficulties present in the literature regarding the challenges of remote teaching during the pandemic, which were highlighted as follows: sudden changes in the handling of technologies and educational platforms for virtual teaching. The second category highlighted the articulation of the teaching and learning process for the applicability of the remote form, since the negative impacts for teaching in times of pandemic were overcome with the advancement of technologies for the mediation of classes held in virtual environments of learning. In this way, remote teaching brought possibilities to the teaching and learning process in the university context in times of the COVID-19 pandemic, where it showed different adaptations to the pedagogical process and academic routine.
\end{abstract}

Keywords: Learning; Teaching; Innovation.

\title{
Resumen
}

La enseñanza a distancia se implementó como una alternativa de emergencia a la enseñanza académica. El estudio tuvo como objetivo identificar, a través de la literatura, los desafíos y posibilidades de la enseñanza a distancia en el contexto universitario durante la pandemia de COVID-19. El estudio se desarrolló a través de una revisión integrativa de la literatura, a través de la síntesis de estudios enfocados en el tema sobre los desafíos y posibilidades de la enseñanza a distancia en el contexto universitario durante la pandemia de COVID-19. 07 artículos fueron utilizados para el estudio. De esta forma, se establecieron dos categorías temáticas, a saber: (I) Desafíos de la docencia a distancia en el contexto universitario durante la pandemia del COVID-19 y (II) Posibilidades de la docencia a distancia en el contexto universitario durante la pandemia del COVID-19. La primera categoría enfatiza las principales dificultades presentes en la literatura sobre los desafíos de la enseñanza a distancia durante la pandemia, las cuales fueron destacadas de la siguiente manera: cambios repentinos en el manejo de tecnologías y plataformas educativas para la enseñanza virtual. La segunda categoría destacó la articulación del proceso de enseñanza y aprendizaje para la aplicabilidad de la modalidad a distancia, ya que los impactos negativos para la enseñanza en tiempos de pandemia fueron superados con el avance de las tecnologías para la mediación de clases realizadas en ambientes virtuales de aprendizaje. De esta manera, la enseñanza a distancia trajo posibilidades al proceso de enseñanza y aprendizaje en el contexto universitario en tiempos de la pandemia del COVID-19, donde mostró diferentes adaptaciones al proceso pedagógico y la rutina académica.

Palabras clave: Aprendiendo; Enseñando; Innovación.

\section{Introdução}

A pandemia da COVID-19 trouxe mudanças para a sociedade em virtude da implementação de medidas voltadas ao distanciamento social para prevenir a disseminação viral. Nesse contexto, as instituições de ensino tiveram que se adaptar às novas estratégias, por meio de tecnologias de fácil acesso para a realização das atividades e formação acadêmica (Souza et al., 2021; Gusso \& Gonçalves, 2020; Lazzarotti, 2015).

O ensino remoto foi implementado de forma emergencial como uma alternativa para o ensino acadêmico como uma 
substituição do ensino presencial. Vale destacar que essa metodologia de ensino proporciona a interação em tempo real dos discentes com os docentes, além da implementação de plataformas com gravações das aulas e atividades relacionadas às aulas ministradas (Bastos et al., 2020; Ferreira et al., 2020).

Deste modo, o ensino superior de forma virtual prevaleceu como uma solução para a educação à distância e formação profissional. Vale destacar que algumas instituições públicas de ensino superior não aderiram ao ensino remoto no início da pandemia. Posteriormente, essas instituições realizaram atividades pedagógicas para a implementação de tecnologias educacionais para a continuidade no processo de formação (Saldanha, 2020; Barros et al., 2022).

Já no ensino superior público prevaleceu a resistência à solução on-line e a percepção das aulas remotas como adesão indesejável à educação a distância, agravamento das desigualdades socioeconômicas dos alunos, dada a diferença das condições de acesso à Internet. Poucas instituições de ensino superior públicas aderiram às chamadas aulas remotas no primeiro semestre de 2020 (Santos \& Zaboroski, 2020; Moraes et al., 2021).

A utilização de tecnologias digitais potencializa a educação do ensino superior, apesar dos benefícios para o ensino durante a pandemia, também existem dificuldades vivenciadas para a adaptação dos alunos, como a falta de acesso e conexão com a internet, infraestrutura inadequada e falta de capacitações dos docentes e discentes para a utilização das plataformas (Nicolini \& Medeiros, 2021). Nesse sentido, surgiu a seguinte indagação: quais os desafios e possibilidades do ensino remoto no contexto universitário durante a pandemia da COVID-19?

Desta forma, a realização do presente estudo justifica-se pela importância de destacar as contribuições do ensino remoto para a formação acadêmica durante a pandemia da COVID-19, bem como mostrar os principais desafios enfrentados para estabelecer subsídios para ampliar a adesão das instituições para essa modalidade de ensino na pandemia, além de superar as dificuldades e desafios existentes.

A pesquisa apresenta relevância para os docentes, profissionais do ensino superior e para a sociedade, por abordar as contribuições do ensino remoto para a efetivação no processo de formação, onde os resultados que serão explanados irão contribuir para o aperfeiçoamento e adesão das tecnologias para o ensino.

O estudo objetivou identificar, por meio da literatura, os desafios e possibilidades do ensino remoto no contexto universitário durante a pandemia da COVID-19.

\section{Metodologia}

O estudo foi desenvolvido através de uma revisão integrativa da literatura, por meio da síntese de estudos voltados à temática referente aos desafios e possibilidades do ensino remoto no contexto universitário durante a pandemia da COVID-19.

A revisão integrativa de literatura trata-se de método que possui a finalidade de sintetizar resultados presentes em estudos científicos voltados à um tema ou questão norteadora, que seja de forma sistemática, ordenada e abrangente, sendo realizada através de seis fases. Deste modo, para a obtenção dos resultados, seguiram-se as seguintes etapas: formulação do problema, coleta dos dados, avaliação, análise e interpretação dos dados coletados e apresentação dos resultados (Mendes et al., 2008).

Para a seleção dos artigos, a busca foi realizada nas seguintes bases de dados: Biblioteca Virtual em Saúde (BVS), Literatura Latino-Americana em Ciências da Saúde (LILACS) e Scientific Electronic Library Online (SciELO), utilizando os Descritores em Ciências da Saúde (DeCS): "aprendizagem", "ensino" e "inovação".

O estudo foi realizado no período de Fevereiro a Março de 2021, onde constituíram-se 65 produções científicas. Os critérios de inclusão dos estudos na pesquisa atual contemplaram: textos disponíveis na íntegra, em língua portuguesa, tipo de documento artigo, compreendidos entre 2020 a 2021, considerados para o corte temporal em virtude do início da pandemia da COVID-19 e mudanças para a realização do ensino universitário. 


\section{Resultados e Discussão}

Em seguida, foi realizada leitura criteriosa e seletiva dos artigos, com a finalidade de analisar as informações acerca do objeto de estudo desta pesquisa. Posteriormente, utilizaram-se como critérios de exclusão: artigos duplicados, fora da temática e os artigos que não eram de acesso aberto e artigos de revisão de literatura, compreendendo 38 artigos para análise, utilizando-se apenas 07 artigos.

O quadro a seguir apresenta a caracterização dos estudos analisados e incluídos para a categorização da revisão, onde aborda o ano de publicação, título, objetivo, método e principais discussões.

Quadro 1 - Caracterização dos artigos incluídos na revisão.

\begin{tabular}{|c|c|c|c|c|c|}
\hline ARTIGO & ANO & TÍTULO & OBJETIVO & MÉTODO & DISCUSSÕES \\
\hline $\mathbf{A 1}$ & 2021 & $\begin{array}{l}\text { Trabalho remoto, } \\
\text { saúde docente e } \\
\text { greve virtual em } \\
\text { cenário de pandemia. }\end{array}$ & $\begin{array}{l}\text { Problematizar mudanças } \\
\text { ocorridas no trabalho de } \\
\text { professoras e professores } \\
\text { da rede particular de } \\
\text { ensino no contexto de } \\
\text { pandemia e sua relação } \\
\text { com a saúde. }\end{array}$ & $\begin{array}{l}\text { Foi construído de forma } \\
\text { compartilhada, entre } \\
\text { professore(a)s e } \\
\text { pesquisadore(a)s. } \\
\text { Fundamenta-se na } \\
\text { pedagogia crítica e } \\
\text { dialógica freireana, cujos } \\
\text { processos valorizam a } \\
\text { formação mútua e } \\
\text { emancipadora. }\end{array}$ & $\begin{array}{c}\text { Dos diálogos empreendidos } \\
\text { durante a construção do texto, } \\
\text { chegamos a quatro importantes } \\
\text { pontos de análise e } \\
\text { problematização, a saber: } \\
\text { trabalho docente em tempos de } \\
\text { isolamento social; mudanças no } \\
\text { processo e na organização do } \\
\text { trabalho; aspectos geracionais e } \\
\text { questões de gênero; saúde } \\
\text { docente, resistências e greve } \\
\text { virtual. }\end{array}$ \\
\hline A2 & 2021 & $\begin{array}{c}\text { Dificuldades e } \\
\text { desafios durante o } \\
\text { ensino remoto na } \\
\text { pandemia: um estudo } \\
\text { com professores do } \\
\text { município de } \\
\text { Queimadas - PB }\end{array}$ & $\begin{array}{c}\text { Compreender as } \\
\text { dificuldades e desafios } \\
\text { enfrentados pelos } \\
\text { professores durante as } \\
\text { aulas no período da } \\
\text { pandemia }\end{array}$ & $\begin{array}{c}\text { Adotou-se uma } \\
\text { abordagem } \\
\text { qualiquantitativa para a } \\
\text { análise e construção dos } \\
\text { resultados. P }\end{array}$ & $\begin{array}{c}\text { Os dados coletados foram } \\
\text { organizados em tabelas e } \\
\text { tratados por meio de estatística } \\
\text { descritiva. Os resultados } \\
\text { obtidos indicaram que a maioria } \\
\text { dos alunos não possuíam } \\
\text { aparelhos eletrônicos adequados } \\
\text { para acompanhar as aulas } \\
\text { remotas, embora tivessem } \\
\text { acesso à internet. }\end{array}$ \\
\hline A3 & 2020 & $\begin{array}{l}\text { Ensino remoto } \\
\text { emergencial na } \\
\text { graduação em } \\
\text { enfermagem: relato } \\
\text { de experiência na } \\
\text { covid-19 }\end{array}$ & $\begin{array}{c}\text { Descrever a experiência } \\
\text { no ensino remoto } \\
\text { emergencial para as } \\
\text { aulas teóricas na } \\
\text { graduação em } \\
\text { Enfermagem em } \\
\text { decorrência da COVID- } \\
19\end{array}$ & $\begin{array}{l}\text { Trata-se de um relato de } \\
\text { experiência pautado na } \\
\text { análise de Paulo Freire } \\
\text { que aborda o processo de } \\
\text { ensino remoto } \\
\text { emergencial das aulas } \\
\text { teóricas ocorrido em um } \\
\text { curso de graduação em } \\
\text { Enfermagem }\end{array}$ & $\begin{array}{l}\text { A experiência de ensino remoto } \\
\text { perpassou pela capacitação e } \\
\text { acompanhamento das docentes } \\
\text { e discentes quanto o uso de } \\
\text { ferramentas virtuais, bem como } \\
\text { pela necessidade de } \\
\text { readequação das estratégias de } \\
\text { ensino, as quais variaram desde } \\
\text { a realização de conferências } \\
\text { virtuais até a elaboração } \\
\text { conjunta de produtos que } \\
\text { compuseram atividades } \\
\text { avaliativas nesse ambiente. }\end{array}$ \\
\hline A4 & 2020 & $\begin{array}{l}\text { O discurso do ensino } \\
\text { remoto durante a } \\
\text { pandemia de } \\
\text { COVID-19 }\end{array}$ & $\begin{array}{c}\text { Descrever o discurso do } \\
\text { ensino remoto durante a } \\
\text { pandemia de COVID-19 } \\
\text { a partir de sua oposição } \\
\text { à educação a distância } \\
\text { (EaD) }\end{array}$ & Estudo de reflexão & $\begin{array}{c}\text { A partir da contribuição da } \\
\text { teoria crítica da tecnologia de } \\
\text { Andrew Feenberg, defende-se } \\
\text { aqui a posição de que a } \\
\text { mediação tecnológica tanto na } \\
\text { educação a distância quanto no } \\
\text { ensino remoto apresenta } \\
\text { limitações e também abre } \\
\text { possibilidades que precisam ser } \\
\text { debatidas }\end{array}$ \\
\hline A5 & 2020 & $\begin{array}{c}\text { Ensino remoto e } \\
\text { pandemia covid-19: } \\
\text { desafios e } \\
\text { oportunidades de } \\
\text { alunos e professores }\end{array}$ & $\begin{array}{c}\text { Analisar as modificações } \\
\text { e adaptações da } \\
\text { educação remota, } \\
\text { buscando apontar os } \\
\text { desafios trazidos pelo } \\
\text { novo coronavírus, bem } \\
\end{array}$ & $\begin{array}{l}\text { As análises em voga são } \\
\text { fruto de pesquisas em } \\
\text { livros, sites e outros } \\
\text { veículos de comunicação }\end{array}$ & $\begin{array}{l}\text { Nessa perspectiva, o presente } \\
\text { artigo tem como objetivo } \\
\text { analisar as modificações e } \\
\text { adaptações da educação remota, } \\
\text { buscando apontar os desafios } \\
\text { trazidos pelo novo coronavírus, }\end{array}$ \\
\hline
\end{tabular}




\begin{tabular}{|c|c|c|c|c|c|}
\hline & & & $\begin{array}{l}\text { como as oportunidades } \\
\text { didáticas do momento }\end{array}$ & & $\begin{array}{l}\text { bem como as oportunidades } \\
\text { didáticas do momento }\end{array}$ \\
\hline A6 & 2020 & $\begin{array}{c}\text { Estratégias e } \\
\text { desafios do ensino } \\
\text { remoto na } \\
\text { enfermagem }\end{array}$ & $\begin{array}{l}\text { Relatar as estratégias } \\
\text { utilizadas por docentes } \\
\text { de cursos de graduação } \\
\text { em Enfermagem do Rio } \\
\text { Grande do Sul e de } \\
\text { Santa Catarina, e os } \\
\text { desafios frente ao ensino } \\
\text { remoto durante a } \\
\text { pandemia pelo novo } \\
\text { coronavírus. }\end{array}$ & $\begin{array}{l}\text { Relato de experiência } \\
\text { desenvolvido por } \\
\text { docentes de cursos de } \\
\text { graduação em } \\
\text { Enfermagem }\end{array}$ & $\begin{array}{l}\text { Em um curto período foi } \\
\text { necessário adaptar o ensino por } \\
\text { meio do uso de novas } \\
\text { tecnologias digitais, a fim de } \\
\text { proporcionar momentos } \\
\text { significativos e que } \\
\text { contribuíssem com a formação } \\
\text { dos estudantes. Dentre os } \\
\text { principais desafios está a } \\
\text { dificuldade de acesso à internet } \\
\text { pelos discentes, o que pode } \\
\text { ocasionar na evasão e interferir } \\
\text { na aprendizagem. Estratégias } \\
\text { como o uso de tecnologias } \\
\text { interativas mostraram-se como } \\
\text { facilitadoras para o ensino } \\
\text { remoto. }\end{array}$ \\
\hline A7 & 2020 & $\begin{array}{l}\text { O ensino remoto } \\
\text { durante a pandemia } \\
\text { de covid-19: } \\
\text { desafios, } \\
\text { aprendizagens e } \\
\text { expectativas dos } \\
\text { professores } \\
\text { universitários de } \\
\text { Educação Física }\end{array}$ & $\begin{array}{l}\text { Identificar os desafios e } \\
\text { as aprendizagens dos } \\
\text { professores } \\
\text { universitários de } \\
\text { Educação Física } \\
\text { relacionadas ao ensino } \\
\text { remoto durante a } \\
\text { pandemia de Covid-19, } \\
\text { bem como as } \\
\text { expectativas em relação } \\
\text { ao ensino pós pandemia, } \\
\text { por meio de um grupo } \\
\text { focal com professores } \\
\text { universitários de } \\
\text { instituições privadas }\end{array}$ & $\begin{array}{l}\text { Pesquisa qualitativa e de } \\
\text { corte transversal, } \\
\text { realizada através de um } \\
\text { grupo focal, que é } \\
\text { utilizado como uma } \\
\text { opção para coletar dados } \\
\text { com ênfase no indivíduo }\end{array}$ & $\begin{array}{c}\text { O distanciamento social } \\
\text { provocado pela pandemia de } \\
\text { Covid-19 e o ensino remoto } \\
\text { emergencial potencializou o } \\
\text { desenvolvimento dos } \\
\text { professores, oportunizando } \\
\text { novas aprendizagens } \\
\text { profissionais. }\end{array}$ \\
\hline
\end{tabular}

Fonte: Elaborada pelos autores.

Emergiram-se duas categorias sobre a temática, sendo elas: (I) Desafios do ensino remoto no contexto universitário durante a pandemia da COVID-19 e (II) Possibilidades do ensino remoto no contexto universitário durante a pandemia da COVID-19.

\section{Categoria 1: Desafios do ensino remoto no contexto universitário durante a pandemia da COVID-19}

As principais dificuldades presentes na literatura referente aos desafios do ensino remoto durante a pandemia foram destacadas da seguinte forma: mudanças repentinas para o manuseio das tecnologias e plataformas educacionais para o ensino virtual, sobrecarga dos professores para a elaboração de aulas e materiais em formato digital, dificuldades para a conexão e instabilidade da internet, falta de capacitações e experiência de professores e alunos com essa modalidade de ensino para a adaptação (Ferreira \& Santos, 2021; Godoi et al., 2020)

Vale destacar que a utilização dos recursos tecnológicos para a ministração de aulas não era uma realidade frequente para o sistema educacional, onde os professores e alunos tiveram que se adaptar às aulas remotas para a continuidade do ensino e formação universitária. Outra realidade evidenciada é a sobrecarga dos profissionais da educação em virtude da preparação e adaptação para o ensino remoto (Saldanha, 2020; Campanella \& Sardinha, 2021; Lazarote)

Nesse sentido, foi necessária a realização de adaptações da metodologia de ensino presencial para o ensino remoto, onde um dos principais desafios elencados foi o curto período de tempo para promover a formação acadêmica e superar as dificuldades dos alunos relacionadas ao acesso à internet e tecnologias educacionais, em virtude de deixar as aulas mais motivacionais, atrativas e significativas (Silveira et al., 2020; Ferreira \& Santos, 2021). 
Mediante a perspectiva dos docentes, ocorreram diversos desafios relacionados ao processo de adaptação e flexibilização das novas formas para explanação do ensino, utilização de novas ferramentas tecnológicas, insegurança para promover o engajamento, dificuldades para a adesão e participação dos alunos durante as aulas no ambiente virtual e elevadas cobranças institucionais para o alcance de resultados satisfatórios (Godoi, 2020; Medeiros et al., 2021).

\section{Categoria 2: Possibilidades do ensino remoto no contexto universitário durante a pandemia da COVID-19}

A pandemia trouxe novas percepções para o ensino e aprendizagem de todo o sistema educacional brasileiro, uma vez que os professores aperfeiçoaram a didática para lecionar os conteúdos presentes na matriz curricular para superar as barreiras impostas pelo distanciamento social. Nesse sentido, a realização de capacitações pedagógicas estiveram presentes nesse processo para a efetivação das aulas virtuais (Santos \& Zaboroski, 2020; Charczuk, 2020).

O cenário atual necessitou de soluções para a realização do ensino e formação universitária, onde o ensino remoto foi uma solução emergencial para contemplar a matriz curricular de ensino e superar a suspensão das atividades institucionais em virtude do distanciamento social. As mídias sociais, plataformas pedagógicas, tecnologias e ambientes virtuais de aprendizagem trouxeram benefícios para o ensino e aprendizagem (Saldanha, 2020).

Dentre as possibilidades referentes à utilização do ensino remoto, destaca-se a articulação do processo de ensino e aprendizagem para a aplicabilidade da forma remota, uma vez que os impactos negativos para o ensino em tempos de pandemia foram superados com o avanço das tecnologias para a mediação das aulas realizadas em ambientes virtuais de aprendizagem. Além disso, foi efetivado o distanciamento social para diminuir a disseminação e infecção viral para as pessoas (Silveira et al., 2020; Coqueiro \& Sousa, 2021; Silveira et al., 2020).

Vale destacar que o novo cenário de ensino durante a pandemia proporcionou novas formas de organização e ferramentas tecnológicas para a flexibilização curricular. Além disso, os professores enfatizaram a aprendizagem relacionada à ampliação do conhecimento de seus alunos em relação ao ensino remoto, onde esses profissionais vislumbram novas mudanças para ensinar que poderão implementar depois da pandemia (Godoi, 2020; Dias, 2021).

\section{Conclusão}

Portanto, o ensino remoto trouxe possibilidades para o processo de ensino e aprendizagem no contexto universitário em tempos de pandemia da COVID-19, onde mostrou diferentes adaptações para o processo pedagógico e rotina acadêmica. Desta forma, a experiência positiva dos professores a essa modalidade tecnológica de ensino em ambientes virtuais de aprendizagem foi uma realidade evidenciada nas pesquisas científicas sobre essa temática, sendo que os desafios foram superados através das capacitações pedagógicas institucionais, bem como a adaptação dos alunos para essa modalidade de ensino.

\section{Referências}

Barros, L. C. M., Portella, M. B., Brito, D. M. C., Gorayeb, A. L. S. \& Andrade, M. C. (2022). Percepção dos docentes sobre o ensino remoto em medicina durante a pandemia pela COVID-19. Research, Society and Development, 11(1), 1-11, http://dx.doi.org/10.33448/rsd-v11i1.25205.

Bastos, M. C, Canavarro, D. A, Campos, L, M, Schulz, R, S, Santos, J, B \& Santos, C. F. (2020). Ensino remoto emergencial na graduação em enfermagem: relato de experiência na COVID-19. Rev Min Enferm, 24 (13), 1-6. https://doi.org/10.5935/1415.2762.20200072.

Campanella, S. C. \& Sardinha, L. F. (2021). O efeito da COVID-19 na estratégia de uma instituição de ensino superior: estudo caso. Revista de economia e empresas empreendedoras, 7 (1), 1-12. https://doi.org/10.29073/e3.v7i1.357

Charczuk, S. B. (2020). Sustentar a Transferência no Ensino Remoto: docência em tempos de pandemia. Educ. Real, 45 (4), 1-12. https://doi.org/10.1590/2175-6236109145.

Coqueiro, N. P. S. \& Sousa, E. C. (2021). A educação a distância (EAD) e o ensino remoto emergencial (ERE) em tempos de Pandemia da Covid 19. Brazilian Journal of Development, 7 (7), 1-15. 10.34117/bjdv7n7-060. 
Dias, E. A Educação, a pandemia e a sociedade do cansaço. (2021). Ensaio: aval. pol. públ. educ. 29 (112), 1-10. https://doi.org/10.1590/S010440362021002901120001 .

Ferreira, S, F \& Santos, A. G. M. (2021). Dificuldades e desafios durante o ensino remoto na pandemia: um estudo com professores do município de Queimadas - PB. Revista científica semana acadêmica, 9(207), 1-12. https://doi.org/2236-6717.

Ferreira, D. H. L., Sugahara, C. R. \& Branchi, B. A. (2020). O impacto da COVID-19 no ensino superior: desenvolvimento de atividades remotas em matemática e em estatística. 16 (43), 1-15. 10.3895/rts.v16n43.12209.

Godoi, M, Kawashima, L, B, Gomes, L. A \& Caneva, C. (2020). O ensino remoto durante a pandemia de covid-19: desafios, aprendizagens e expectativas dos professores universitários de Educação Física. Research, Society and Development, 9 (10), 1-20. https://doi.org/10.33448/rsd-v9i10.8734.

Gusso, H. L. \& Gonçalves, V. M. (2020). Ensino Superior Em Tempos De Pandemia: Diretrizes À Gestão Universitária. Educ. Soc, 41 (12), 1-13. https://doi.org/10.1590/ES.238957.

Lazzarotti, A., Cruvinel, F., Silva, A. M, Silva, M. Z. \& Almeida, G. C. F. (2015). A dinâmica,os principais problemas ecomo qualidades no desenvolvimentode um curso delicenciatura em educação física na modalidade à distância. Pensar a Pratica, 18 (3), 636-5. https://doi.org/10.5216/rpp.v18i3.34504

Medeiros, A. A., Batiston, A. P., Souza, L. A., Ferrari, F. P. \& Barbosa, I. R. (2021). Análise do ensino em fisioterapia no Brasil durante a pandemia de COVID-19. Fisioter. Mov, 34 (5), 1-10. https://doi.org/10.1590/fm.2021.34103.

Mendes, K. D. S., Silveira, R. C. C. P., \& Galvão, C. M. (2008). Revisão integrativa: método de pesquisa para a incorporação de evidências na saúde e na enfermagem. Texto Contexto Enferm, 17(4), 758-64. https://doi.org/10.1590/S0104-07072008000400018.

Moraes, E. M., Costa, W. C. L. \& Passos, V. M. A. (2021). Ensino remoto: percepções de professores que ensinam matemática. Matemática e suas tecnologias, 6 (2), 1-13. 10.23926/RPD.2021.v6.n2.e029.id1109

Nicolini, C. \& Medeiros, K. E. G. (2021). Aprendizagem histórica em tempos de pandemia. Estud. Hist., 34 (73), 1-10. https://doi.org/10.1590/S2178149420210204

Saldanha, L. C. D. O discurso do ensino remoto durante a pandemia de COVID-19. (2020). Revista educação e cultura contemporânea, 17(50), 124-144. http://dx.doi.org/10.5935/2238-1279.20200080.

(2020).

Santos, J. R., \& Zaboroski, E. A. Ensino remoto e pandemia covid-19: desafios e oportunidades de alunos e professores. Revista Interacções, 2 (51), $41-57$. https://doi.org/10.25755/int.20865.

Silus, A., Fonseca, A. L. C. \& Jesus, D. L. N. (2020). Desafios do ensino superior brasileiro em tempos de pandemia da Covid-19: repensando a prática docente. Liinc, 16 (2), 1-14. https://doi.org/10.18617/liinc.v16i2.5336.

Souza, K. R., Santos, G. B., Rodrigues, A. M. S., Felix, E. M., Gomes, L., Rocha, G, L., Conceição, R. C. M., Rocha, F. S. \& Peixoto, R. B. (2021). Trabalho remoto, saúde docente e greve virtual em cenário de pandemia. Trabalho, Educação e Saúde, 19 (4), 1-24, 2021. 10.1590/1981-7746-sol00309.

Silveira, A. Santos, N. O., Wilhelm, L. A., Socool, K. L. S., Tisott, K. L. S., \& Prates, L. A. (2020). Estratégias E Desafios Do Ensino Remoto Na Enfermagem. Enferm. Foco, 11 (5), 98 (103). 10.3895/rts.v16n43.12209. 